\title{
A dimensão ambiental na Proposta Pedagógico-Curricular para a formação de pedagogos e pedagogas
}

\section{The environmental dimension in the Pedagogical-Curricular Proposal for the training of pedagogues}

\section{La dimensión ambiental en la Propuesta Pedagógico-Curricular para la formación de pedagogos y pedagogas}

\author{
Cássia Machado Ribeiro Dantas' \\ Maria Inêz Oliveira Araújo
}

\section{Resumo}

A pedagogia como campo de conhecimento e investigação ou ciência prática da educação que estuda o fenômeno educativo em sua globalidade/complexidade perpassa a implementação da Educação Ambiental. Este texto objetiva explicitar como a proposta pedagógico-curricular do curso de Pedagogia da Universidade Federal de Sergipe (UFS)/São Cristóvão contribui para a formação de professores(as) na perspectiva ambiental. Para tanto, foi analisado o Projeto Pedagógico (PPC), bem como o currículo do curso supracitado. Verificou-se que as contribuições do conhecimento ambiental-ecológico para o campo da Educação Ambiental são incipientes e se conjectura sua possibilidade a partir da disciplina Educação e Ética Ambiental, a qual compõe o núcleo de estudos básicos e, mais especificamente, o eixo campos do conhecimento educacional, uma vez que esse núcleo articulará princípios e concepções de diferentes áreas do conhecimento com pertinência ao campo da pedagogia e dos estudos das relações entre a educação e as problemáticas centrais da sociedade contemporânea, dentre elas a sustentabilidade.

Palavras-chave: Educação Ambiental. Formação inicial. Pedagogia.

\begin{abstract}
Pedagogy as a field of knowledge and investigation or practical science of education that studies educational actions permeates the implementation of environmental education. This text aims to explain the contributions of ecological concepts to the educational process from an environmental perspective, present in the pedagogical-curricular proposal of the Pedagogy course at the Federal University of Sergipe (UFS)/São Cristóvão. Therefore, the Pedagogical Project was analyzed, as well as the curriculum of the aforementioned course. We found that the contributions of environmentalecological knowledge to the field of environmental education are incipient and its possibility is conjectured from the subject Environmental Education and Ethics, which makes up the core of basic studies and, specifically, the axis of fields of educational knowledge, since this nucleus, will articulate principles and conceptions of different areas of knowledge relevant to the field of pedagogy and studies of the relations between education and the central problems of contemporary society, including sustainability.
\end{abstract}

Keywords: Environmental education. Initial formation. Pedagogy.

\footnotetext{
1 Universidade Federal de Sergipe.

2 Universidade Federal de Sergipe.
} 


\section{Resumen}

La pedagogía como campo de conocimiento e investigación o ciencia práctica de la educación que estudia las acciones educativas impregna la implementación de la educación ambiental. Este texto tiene como objetivo explicar los aportes de los conceptos ecológicos al proceso educativo desde una perspectiva ambiental, presente en la propuesta pedagógico-curricular del curso de Pedagogía de la Universidad Federal de Sergipe (UFS)/São Cristóvão. Por tanto, se analizó el Proyecto Pedagógico, así como el plan de estudios del curso mencionado. Encontramos que los aportes del conocimiento ambiental-ecológico al campo de la educación ambiental son incipientes y su posibilidad se conjetura a partir de la asignatura Educación y Ética Ambiental, que conforma el núcleo de los estudios básicos y, en concreto, el eje de los campos del conocimiento educativo. , desde este núcleo, articulará principios y concepciones de diferentes áreas del conocimiento relevantes para el campo de la pedagogía y estudios de las relaciones entre la educación y los problemas centrales de la sociedad contemporánea, incluida la sostenibilidad.

Palabras clave: Educación ambiental. Formación inicial. Pedagogía.

\section{Introdução}

Por vezes, é muito consumo e pouca consciência. Consciência para um uso controlado e equilibrado, para um descarte correto e para tantos outros atos humanos que signifiquem o cuidado e o respeito com a natureza e o nosso planeta Terra. A imprescindibilidade da consciência socioambiental e do respeito ou de atitudes e valores éticos para com o ambiente é um motivo tanto quanto forte para a justificação da Educação Ambiental enquanto um processo "[...] por meio do qual as pessoas apreendam como funciona o ambiente, como dependemos dele, como o afetamos e como promovemos a sua sustentabilidade." (DIAS, 2004, p. 100).

Como escreveu Kant (1999, p. 16), "[...] a natureza humana será sempre melhor desenvolvida e aprimorada pela educação". Ainda de acordo com o filósofo, o ser humano é o único ser vivo que precisa ser educado, pois, diferentemente de um animal que possui seu próprio instinto ou uma razão exterior que lhe provê antecipadamente todas as suas necessidades, o homem/a mulher precisa formar sua própria razão ou o projeto de sua conduta por meio da educação. E, por esta se tratar de uma condição especificamente humana e de reflexão crítica sobre o mundo ou o ambiente do qual fazemos parte, consideraremos a relevância da Educação Ambiental como elemento constituinte do currículo nas escolas na condição de dimensão do processo educativo.

Segundo o artigo 26, parágrafos $1^{\circ}$ e $7^{\circ}$, da Lei $n^{\circ} 9.394$, que estabelece as Diretrizes e Bases da Educação Nacional, os currículos do Ensino Fundamental e do Ensino Médio devem ter base nacional comum e, dentre outros, incluir a Educação Ambiental de forma integrada aos conteúdos obrigatórios (BRASIL, 1996). Nesse aspecto, a Base Nacional Comum Curricular (BNCC), documento normativo homologado em 2017, definiu o conjunto de aprendizagens essenciais para os(as) alunos(as) da Educação Básica, as quais asseguram o desenvolvimento de 10 (dez) competências gerais, dentre as quais: 
Argumentar com base em fatos, dados e informações confiáveis, para formular, negociar e defender ideias, pontos de vista e decisões comuns que respeitem e promovam os direitos humanos, a consciência socioambiental e - consumo responsável em âmbito local, regional e global, com posicionamento ético em relação ao cuidado de si mesmo, dos outros e do planeta. (BRASIL, 2017, p. 9, grifo nosso).

A partir das orientações dispostas na BNCC, o Currículo de Sergipe para a Educação Infantil e o Ensino Fundamental, homologado em 2019, tem como base 8 (oito) princípios norteadores, os quais objetivam o desenvolvimento integral do(a) aluno(a), sendo eles: Colaboração; Respeito à diferença; Criticidade; Inclusão; Equidade; Autonomia; Sustentabilidade; e Criatividade. O princípio da sustentabilidade está descrito da seguinte maneira:

Desenvolver a capacidade de interagir com o mundo atual, satisfazendo suas necessidades de forma consciente e responsável, comprometendo-se com as gerações futuras, seja no âmbito ambiental, social ou econômico. (SERGIPE, 2019, p. 12).

Todavia, essa concepção de sustentabilidade presente no Currículo de Sergipe está mais próxima do conceito de desenvolvimento sustentável, na medida em que, ao estabelecer que o princípio da sustentabilidade perpassa as mudanças atitudinais com vistas à utilização do ambiente e de seus recursos para satisfações pessoais em primeiro plano, deixando o compromisso com o cuidado desse espaço em lugar secundário no discurso, desvela um alinhamento do documento aos ideais e interesses do sistema econômico capitalista, visto que, em conformidade com Boff (2018, p. 116 , grifo do autor),

Sustentabilidade é toda ação destinada a manter as condições energéticas, informacionais, físico-químicas que sustentam todos os seres, especialmente a Terra viva, a comunidade de vida, a sociedade e a vida humana, visando sua continuidade e ainda atender as necessidades de geração presente e futuras, de tal forma que os bens e serviços naturais sejam mantidos e enriquecidos em sua capacidade de regeneração, reprodução e coevolução.

O entendimento de Boff (2018) acerca da sustentabilidade nos leva a perceber que o seu princípio circunda uma compreensão sistêmica de percepção do mundo e da problemática socioambiental desvelando-se integradora e holística, sem colocar o ser humano como usufuinte do ambiente, mas como ser integrado a ele e comprometido com o seu cuidado e com as formas de vida coletivas e colaborativas, a fim de promover o sustento da Terra.

O pensamento de Boff (2018) coaduna a visão de Educação Ambiental disposta nas Diretrizes Curriculares Nacionais para a Educação Ambiental (DCNEA), que a vê como 
dimensão educacional que "visa à construção de conhecimentos, ao desenvolvimento de habilidades, atitudes e valores sociais, ao cuidado com a comunidade de vida, a justiça e a equidade socioambiental, e a proteção do meio ambiente natural e construído" (BRASIL, 2012, p. 02).

Nesse sentido, a BNCC e o Currículo de Sergipe para a Educação Infantil e o Ensino Fundamental, ao não disporem sobre um entendimento concernente à Educação Ambiental, reduzindo-a a um tema interdisciplinar, vão de encontro às disposições presentes nas DCNEA e à compreensão integrada de sustentabilidade defendida por Boff (2018), apresentando uma visão reducionista e conservacionista da Educação Ambiental em vez de uma dimensão do processo formativo como deveria ser.

Contudo, ainda que esteja presente desse modo reducionista na BNCC e no Currículo de Sergipe, o desenvolvimento da Educação Ambiental na práxis pedagógica ultrapassa os grilhões do currículo explícito porque pode ocorrer no cotidiano escolar, de modo formal ou não formal, por meio de atividades curriculares e extracurriculares. Porém, para que essa transcendência conceitual aconteça, é necessário que os(as) professores(as) tenham conhecimento do que vem a ser a Educação Ambiental e a compreendam como dimensão, e isso implica acesso a uma formação docente inicial e continuada adequada, pois, segundo Araujo (2004, p. 102), "para ensinar sob a perspectiva da educação ambiental, o professor, além de estar munido de saberes pedagógicos (formação pedagógica), deve estar preparado para acompanhar, entender e discutir as relações e o dinamismo que regem o ambiente".

No entanto, a Resolução CNE/CP n²/2019, que define as Diretrizes Curriculares Nacionais para a Formação Inicial de Professores para a Educação Básica e institui a Base Nacional Comum para a Formação Inicial de Professores da Educação Básica (BNCFormação), não dispõe sobre a necessidade de trabalhar a Educação Ambiental na formação docente, tampouco a entende como uma dimensão do processo formativo, reduzindo-a a uma competência a ser desenvolvida, tal qual ocorre na BNCC e no Currículo de Sergipe, demonstrando, desse modo, um retrocesso entre os avanços conquistados ao longo da história.

De acordo com Cambi (1999, p. 638), a partir dos anos 1980 novas emergências educativas surgiram a partir de transformações sociais e culturais, modificando "[...] as conotações sociais da pedagogia, recolocando-a de maneira nova no âmbito da sociedade e enfatizando os aspectos sociológicos (e políticos) do seu saber." Entre essas emergências encontra-se o problema ecológico causado pela industrialização em descontrole e pelo domínio e pela exploração da natureza. E, nesse aspecto, Cambi (1999) explicita a relação entre a ecologia e a pedagogia.

$\mathrm{Na}$ concepção do autor:

A ecologia também deixou uma marca bastante profunda na reflexão pedagógica: ela também submeteu à crítica muitos preconceitos culturais e educativos (pense-se no domínio, no domínio-exploração do ambiente); pôs em destaque novos valores e novos modelos antropológicos e culturais, 
exaltando uma relação soft entre homem e ambiente e as características psicológicas que a realizam e/ou favorecem: a compreensão, o respeito, o intercâmbio não violento etc., de modo a construir um sujeito sensivelmente novo em relação ao passado. (CAMBI, 1999, p. 639-640, grifo do autor).

As inter-relações descritas pela ecologia sofrem pressões do modo de vida vigente na sociedade. O ambiente do qual fazemos parte sofre pressão das relações - sejam elas sociais, religiosas, econômicas, culturais ou ecológicas. Conhecer as relações ecológicas é importante para desencadear no ser humano a tomada de consciência sobre a sua responsabilidade com o futuro da sociedade e do meio ambiente. Nesse sentido, o autor argumenta que:

A pedagogia acolheu, em particular, a noção de ambiente (visto não como um simples habitat a percorrer e usar, mas como um 'nicho ecológico' a respeitar e preservar - já que também não reprodutível depois de destruído - em cada aspecto e forma: dos animais às plantas, à morfologia), que penetrou tanto na elaboração teórica de modelos de formação quanto na prática educativa e didática. (CAMBI, 1999, p. 640, grifo do autor).

Faz-se mister para essa perspectiva de educação uma formação docente que aborde a problemática socioambiental com vistas a formar também educadores(as) ambientais, isto é, sujeitos capazes de agir em prol da ressignificação de uma "representação de mundo antropocêntrica e colonial, geradora da degradação ecossistêmica e da problemática socioambiental" (MODESTO; SANTOS, 2020, p. 533) e, por conseguinte, para a transformação da realidade por intermédio do entendimento de uma Educação Ambiental que "para além do contato com a natureza, busca a interdisciplinaridade, integrando, assim, as emoções, o respeito com os indivíduos, a colaboração, o sentimento de pertencimento, entre outros aspectos essenciais para a formação dos indivíduos" (RODRIGUES; SAHEB, 2018 , p. 574-575).

Dessa forma, o objetivo do presente escrito consiste em explicitar como a proposta pedagógico-curricular do curso de Pedagogia/UFS, Campus São Cristóvão, contribui para a formação de professores(as) na perspectiva ambiental.

Para tanto, realizou-se uma pesquisa documental. "Os passos para a realização de uma pesquisa documental são os seguintes: a) determinar os objetivos da pesquisa; $b$ ) escolher os documentos; c) acessar os documentos; d) analisar os documentos; e e) redigir o relatório." (MOREIRA; CALEFFE, 2008, p. 75). Assim sendo, após termos elaborado o objetivo do estudo, foram selecionados os seguintes documentos: o Projeto Pedagógico do Curso de Pedagogia (PPC) da Universidade Federal de Sergipe (UFS/Campus São Cristóvão), a Resolução n 25/CONEPE/2008, a qual aprova o PPC, o ementário e os programas ou planos de ensino dos componentes curriculares. Posteriormente a isso, foram providenciados meios para acessá-los. 
Com relação aos dois primeiros documentos, estes foram solicitados em pedido formal enviado ao Departamento de Apoio Didático Pedagógico (DEAPE) e ao Departamento de Educação (DED) da Universidade Federal de Sergipe. No que se refere aos programas dos componentes curriculares, estes se encontram disponíveis no Sistema Integrado de Gestão de Atividades Acadêmicas (SIGAA) da instituição.

A análise desses documentos textuais/institucionais se deu à luz dos referenciais teóricos utilizados nesse estudo. De acordo com Flick (2009, p. 234), os documentos não devem ser utilizados como contêineres de informação, mas sim analisados como "dispositivos comunicativos", pois "[...] representam uma versão específica de realidades construídas para objetivos específicos." Dessa forma, com a finalidade de explorar esse contexto e suas características, ou seja, a proposta para formação docente na perspectiva ambiental, esta pesquisa é de caráter qualitativo, afinal na pesquisa qualitativa a preocupação do(a) pesquisador(a) não é com a representatividade numérica, mas com o aprofundamento da compreensão (GOLDENBERG, 2013). Por fim, este escrito científico é resultado da útima etapa da pesquisa documental - que foi a redação do relatório final.

A educação na perspectiva ambiental: analisando a proposta pedagógico-curricular do curso de Pedagogia da Universidade Federal de Sergipe (UFS/Campus São Cristóvão)

De acordo com Boton et al. (2010), a Educação Ambiental avança nas universidades mediante a ambientalização curricular, caracterizada pela internalização nos seus currículos e nas suas práticas cotidianas da atual problemática ambiental ou da reflexão sobre as questões socioambientais.

A abordagem ambiental está na agenda da Universidade Federal de Sergipe (UFS). De acordo com o seu mais recente Plano de Desenvolvimento Institucional (PDI/UFS), é missão da instituição "Contribuir para o progresso da sociedade por meio da geração de conhecimento e da formação de cidadãos críticos, éticos e comprometidos com o desenvolvimento sustentável." (UFS, 2016, p. 15, grifo nosso). Nota-se aqui a convergência da visão da instituição supracitada com os princípios reducionistas presentes na BNCC e no Currículo de Sergipe, que endossam a defesa de uma "sustentabilidade" aliada ao sistema econômico capitalista e, por seu turno, ao desenvolvimento sustentável. Este, por sua vez, é assentado na ideia de crescimento econômico com foco na produção de lucro dentro de um sistema econômico que já se configura como inviável através de um modus operandi industrialista/capitalista/consumista (BOFF, 2018).

No que se refere à atual proposta pedagógica e, consequentemente, ao currículo atual do curso de Pedagogia da Universidade Federal de Sergipe (UFS), Campus Professor José Aloísio de Campos, regulamentados pela Resolução $n^{\circ}$ 25/2008/CONEPE, foram reformulados em atendimento às orientações da Resolução CNE/CP $n^{0} 1 / 2006$, a qual instituiu as Diretrizes Curriculares Nacionais para o Curso de Pedagogia no Brasil.

Dessa forma, o curso está destinado à formação de professores(as) para o ensino das disciplinas pedagógicas nos cursos de nível médio, para o exercício da docência na Educação 
Infantil e nos anos iniciais do Ensino Fundamental e, também, para as atividades de gestão, coordenação e assessoramento pedagógico em órgãos do sistema educacional e em espaços não escolares (UFS, 2008). São profissionais que, segundo o projeto, terão adquirido, ao longo do desenvolvimento das atividades curriculares e complementares do curso, a competência, dentre outras, de "[...] analisar e criar processos educativos que possam interferir como estratégia de desenvolvimento socialmente justo e ecologicamente sustentável em ambientes escolar e não escolar [...]." (UFS, 2008, p. 2, grifo nosso).

Podemos verificar, a partir dessa competência, a abordagem da Educação Ambiental pela proposta pedagógica do curso em destaque. Observamos também a ausência de uma visão reducionista da Educação Ambiental, a partir da qual se enfatizam apenas os seus aspectos biológicos/ecológicos, em detrimento da compreensão da existência e da importância da interdependência econômica, política, social e ecológica da sociedade. Está nítido também que a proposta pedagógica analisada considera a relação sociedadenatureza ou ser humano-ambiente, como se pode constatar em uma das habilidades a serem adquiridas no decorrer do curso, a saber: "[...] apresentar qualidades pessoais de se auto-compreender enquanto indivíduo singular e constituído na interação com o outro, com seu grupo social e como elemento pertencente à espécie humana [...]." (UFS, 2008, p. 3, grifo nosso).

De acordo com o filósofo norte-americano John Dewey, os seres humanos são seres biológicos em contínua interação com a natureza (SCHMITZ, 1980). Quando harmoniosa, essa relação ser humano-meio tende a contribuir para a manutenção da qualidade de vida e para o equilíbrio das relações sociais, políticas e econômicas. Mas o que se percebe é a necessidade de educar crianças, jovens e adultos para tal relação dado o avanço da degradação ambiental.

Immanuel Kant (1999), filósofo alemão, já no século XVIII comunicava a respeito da importância de cada geração vindoura dar um passo a mais ao estar em posse dos conhecimentos das gerações precedentes. No entanto, parece que estamos vivenciando uma condição de involução da espécie humana no sentido do cuidado e respeito com o planeta para as futuras gerações, mesmo com o avanço da ciência, da tecnologia e do grande acúmulo de conhecimento gerado até os dias atuais. É uma espécie de paradoxo.

Se considerarmos a agressão ao ambiente como uma barbárie, poderemos trazer Adorno (1995) para essa discussão. O filósofo moderno afirma ser a tentativa de superar a barbárie uma ação urgente e decisiva para a sobrevivência da humanidade, inclusive defende que esse seja o objetivo prioritário da educação. Adorno define a barbárie da seguinte maneira:

[...] estando na civilização do mais alto desenvolvimento tecnológico, as pessoas se encontrem atrasadas de um modo peculiarmente disforme em relação a sua própria civilização - e não apenas por não terem em sua arrasadora maioria experimentado a formação nos termos correspondentes ao conceito de civilização, mas também por se encontrarem tomadas por uma 
agressividade primitiva, um ódio primitivo ou, na terminologia culta, um impulso de destruição, que contribui para aumentar ainda mais o perigo de que toda esta civilização venha a explodir, aliás uma tendência imanente que a caracteriza. (1995, p. 155).

Segundo Morin (2011), o século XX constituiu-se na era da barbárie, e sua herança foi de morte e de nascimento simultaneamente. Os dois novos poderes de morte são, primeiramente, a possibilidade de extinção global da humanidade pelas armas nucleares e, segundo, a possibilidade de morte ecológica, ao se descobrir, a partir dos anos 1970, que os dejetos, as emanações e as exalações do desenvolvimento técnico-industrial urbano degradam a biosfera "[...] e ameaçam envenenar irremediavelmente o meio vivo ao qual pertencemos: a dominação desenfreada da natureza pela técnica conduz a humanidade ao suicídio." (MORIN, 2011, p. 62). É legado desse século, também, o nascimento de novas esperanças para a transformação global, inclusive do próprio gênero humano, na busca de solidariedade e responsabilidade, vislumbrando uma "cidadania terrestre" (MORIN, 2011 , p. 63) ou uma consciência e um sentimento de pertencimento à Terra, considerada primeira e última pátria.

Pode-se ponderar que a Educação Ambiental contribui para a tentativa de suplantar a barbárie da degradação ambiental (no sentido holístico e integral do termo), uma vez que, segundo Dias (2004), a Educação Ambiental caracteriza-se como um processo educativo que pretende desenvolver conhecimento, compreensão, habilidades e motivação para adquirir valores, mentalidades e atitudes necessários para lidar com os problemas ambientais e encontrar soluções sustentáveis para eles. Essa educação, que se constitui, dentre outros, pelo aspecto ético, subsidia a produção do conhecimento preocupada com a humanização e a realidade e a universalidade da vida, além de que elimina o individualismo e estimula a cooperação e solidariedade das novas gerações, possibilitando a formação de um ser humano

[...] capaz de construir opções infinitas para uma cidadania globalizada, na qual se realize um desenvolvimento sustentável que satisfaça as necessidades das gerações presentes sem sacrificar as gerações futuras; que promova qualidade de vida sem comprometer a sustentabilidade dos ecossistemas, que transforme as relações de gênero, que estimule a vida comunitária e a cidadania e efetive o direito inalienável das crianças. (AHLERT, 1999, p. 159).

Como afirma Saviani (1999), a educação relaciona-se dialeticamente com a sociedade, sendo um instrumento importante (não determinante principal) para a transformação social, e nós, como agentes sociais, somos elementos constitutivos da prática social, a qual é o ponto de partida e chegada ou o fundamento e a finalidade da prática educativa, que, nas palavras de Freire (2017), deve ter como sentido transformar a realidade e não apenas adaptar-se a ela. 
Nesse sentido, a educação trata-se de um processo global arraigado na prática social e inerente à constituição do homem e da sociedade e, portanto, integrante da vida social, política, econômica e cultural (LIBÂNEO, 2010). Pode-se observar na proposta pedagógicocurricular analisada a afirmação do seu compromisso social, como se pode ler a seguir: "O curso de Pedagogia da Universidade Federal de Sergipe desenvolve uma formação para educadores voltada para a formação integral, priorizando as relações entre o corpo docente e discente e o compromisso social no campo da educação." (UFS, 2007, p. 22). Se a concepção de formação é pautada por esse compromisso, igualmente ocorre com o perfil do(a) egresso(a), onde se lê:

Como perfil, o Licenciado em Pedagogia deve, antes de tudo, se comprometer com a formação societária de bases radicalmente democráticas através de uma atitude ética de solidariedade, honestidade, sentimento de indignação frente às injustiças sociais e humanas e compromisso com as transformações que beneficiam a maioria da população, objetivando a formação de um pedagogo/educador capaz de incorporar à sua prática profissional as dimensões do conhecer, analisar, sistematizar, propor e superar os desafios existentes na realidade sócio-educacional atual. (UFS, 2008, p. 2, grifo nosso).

Diferentemente do que é apresentado na missão exposta no PDI da Universidade Federal de Sergipe, o PPC do curso de Pedagogia dessa instituição enfatiza uma visão que corrobora os princípios da Educação Ambiental Crítica, que, segundo Loureiro e Layrargues (2013, p. 64), prioriza "questionar os condicionantes sociais historicamente produzidos que implicam a reprodução social e geram a desigualdade e os conflitos ambientais".

O projeto pedagógico também explana as seguintes questões centrais para o curso:

Por isso, definimos que a natureza do curso de Pedagogia se expressa na centralidade das questões de ordem educacional em seus aspectos sociológicos, filosóficos, culturais e do desenvolvimento cognitivo, afetivo e social do ser humano. Deste ponto de vista, a formação do profissional da área de educação deve pautar-se em uma ampla base formal, cultural e política, norteadora de uma relação de responsabilidade desse profissional com a educação, com a escola pública e com sociedade em geral. (UFS, 2007, p. 20, grifo nosso).

Essas são questões que nos direcionam para a própria concepção de pedagogia adotada pelo curso, quais sejam:

Pedagogia é uma práxis que integra, articula e transversaliza conhecimentos e processos de outros campos científicos que contribuem para a produção de novas epistemologias a partir do seu objeto, que é a sua prática educativa. $\mathrm{O}$ 
curso de Pedagogia, em seus diferentes aspectos, também se constitui em um campo científico e investigativo que irá se preocupar com a prática educativa. (UFS, 2007, p. 22-23, grifo no original).

De acordo com Cambi (1999), é a partir dos escritos de Kant que a pedagogia assume um caráter científico. Ou seja, de uma arte da educação mecânica, passa-se a uma arte da educação raciocinada que obedece a um plano para o desenvolvimento e amadurecimento humano. Assim, "É preciso colocar a ciência em lugar do mecanicismo, no que tange à arte da educação; de outro modo, esta não se tornará jamais um esforço coerente; e uma geração poderia destruir tudo o que uma outra anterior tivesse edificado." (KANT, 1999, p. 22).

De lá para cá, exatamente em meados do século XX, a pedagogia transformou-se de uma ciência da educação ou de um saber unitário e fechado para um saber plural e aberto ou das ciências da educação, as quais representam os saberes especializados necessários para o enfrentamento da complexidade dos fenômenos educativos (CAMBI, 1999).

Assim, segundo Libâneo (2010), a pedagogia é uma das ciências da educação que se distingue das demais por estudar o fenômeno educativo em sua globalidade. Recorre a conceitos e métodos de outras ciências da educação (como a Sociologia, a Psicologia, a Filosofia, por exemplo) enquanto busca instituir seus próprios, porém se conserva em um campo de estudos com identidade e problemáticas próprias.

Ainda conforme o autor, a pedagogia é um campo de conhecimento que investiga a natureza e as finalidades da educação em uma dada sociedade. Ou seja, é uma ciência prática, o que a constitui, para além de um campo de conhecimento, um campo de investigação também, "[...] cuja fonte é a própria prática educativa e os aportes teóricos providos pelas demais ciências da educação e cuja tarefa é o entendimento, global e intencionalmente dirigido, dos problemas educativos." (LIBÂNEO, 2010, p. 136).

Então, é particular da pedagogia a investigação da realidade educativa por meio de enfoques diferentes. Assim sendo, podemos elucubrar a possibilidade de a ecologia contribuir, a partir de seu campo teórico e de investigação, com a pedagogia. Vejamos a seguir que Libâneo (2010, p. 136-137) menciona os aportes da biologia.

A ciência pedagógica dispõe de ramos de estudo dedicados aos vários aspectos da prática educativa (teoria da educação, política educacional, teoria do ensino (didática), organização escolar, história da Pedagogia). Esse complexo de conhecimentos funda-se no entendimento de que a Pedagogia compõe o conjunto das ciências da educação, mas se destaca delas por assegurar a unidade e dar sentido às contribuições das demais ciências, já que lhe cabe o enfoque globalizante e unitário do fenômeno educativo. Fica claro que, desse ponto de vista, os conhecimentos obtidos dessas ciências, à medida que se referem ao fenômeno educativo, convertem-se em conhecimentos pedagógicos, única razão para a existência de uma sociologia da educação, psicologia da educação, biologia da educação etc. (grifo do autor). 
Vimos, anteriormente, que o ecológico é um dos aspectos da educação na perspectiva ambiental. A articulação e a integração de teorias e estudos ecológicos podem ser proporcionadas no curso de Pedagogia da UFS do Campus São Cristóvão por meio de um dos núcleos que constituem a estrutura do curso supracitado: o Núcleo de Estudos Básicos, o qual é nomeado pela Resolução CNE/CP n 2/2015 de "I - núcleo de estudos de formação geral, das áreas específicas e interdisciplinares, e do campo educacional, seus fundamentos e metodologias, e das diversas realidades educacionais, [...]." (p. 9).

Esse núcleo, segundo as DCN-Pedagogia, em consonância com a resolução citada no parágrafo anterior, articulará a "[...] aplicação de princípios, concepções e critérios oriundos de diferentes áreas do conhecimento, com pertinência ao campo da Pedagogia, que contribuam para o desenvolvimento das pessoas, das organizações e da sociedade; [...]." (BRASIL, 2006, p. 3, grifo nosso).

Dessa maneira, na proposta pedagógico-curricular analisada, o Núcleo de Estudos Básicos está formado por 7 (sete) eixos temáticos "[...] definidos entre os professores do Departamento, a fim de contemplar suas áreas de investigação." (BRETAS, 2009, p. 52). São eles: a) Campos do Conhecimento Educacional; b) Sociedade, Estado e Educação; c) Prática Educativa (crianças, adolescentes, jovens e adultos); d) Currículo, Conhecimento e Diversidade Sócio-Cultural; e) Política e Gestão em Educação; f) Docência, Infância, Juventude e Cultura; e g) Educação e Comunicação.

No que se refere ao eixo Campos do Conhecimento Educacional, este é composto por disciplinas que representam os aportes teóricos das ciências da educação para o campo de investigação da pedagogia. São elas: Fundamentos Filosóficos da Educação; Fundamentos Sociológicos da Educação; Introdução à História da Educação; Antropologia na Educação; Psicologia do Desenvolvimento e da Aprendizagem / e I/; Fundamentos da Investigação Científica; Pesquisa em Educação e Política e Educação.

A inserção dessas disciplinas no currículo do curso reflete a especificidade da pedagogia em "estudar o fenômeno educativo na sua globalidade" (LIBÂNEO, 2010, p. 96) ou sob a perspectiva das diversas dimensões, visando a formação do ser humano em sua integralidade: cognitiva, social, afetiva, física, estética e ética. Morin (2011, p. 36) explica que "[...] há um tecido interdependente, interativo e inter-retroativo entre o objeto de conhecimento e seu contexto, as partes e o todo, o todo e as partes, as partes entre si."

A educação na perspectiva ambiental destaca essa ideia, pois considera o que Morin (2011, p. 93) também denomina de caráter ternário da condição humana ou a "tríade indivíduo $\leftrightarrow$ sociedade espécie", ou seja, o ser humano é indivíduo, mas também é parte da sociedade e parte da espécie. Nesse sentido, o ser humano é, a um só tempo, biológico, psíquico, social, afetivo e racional, constituindo-se em uma unidade complexa como a sociedade, a qual é composta pelas dimensões histórica, econômica, sociológica, religiosa, política.

Desse modo, é inerente à educação evidenciar o contexto e o global ou o complexo com o propósito de construir um conhecimento pertinente que reconheça essa 
multidimensionalidade tanto do ser humano quanto da sociedade e, por conseguinte, dos problemas que cercam a humanidade, como o socioambiental, por exemplo. "A educação para a complexidade consiste em compreender que todos fazem parte do problema, mas também da solução [...]." (PERRENOUD, 2005, p. 161).

É nesse eixo supracitado que também está inserida a disciplina destinada à Educação Ambiental: Educação e Ética ambiental, componente obrigatório com carga horária de 60 (sessenta) horas. No Quadro 01, a seguir, apresentamos em que consiste esse componente curricular.

Quadro 1 - Programa da disciplina Educação e Ética Ambiental do curso de Pedagogia/UFS do Campus São Cristóvão

\begin{tabular}{|c|l|}
\hline ITEM & \multicolumn{1}{c|}{ DESCRIÇÃO } \\
\hline EMENTA & $\begin{array}{l}\text { Aspectos históricos e normativos da Educação Ambiental no mundo e no Brasil. } \\
\text { Epistemologia ambiental. Ambiente, crise ambiental e o movimento ambientalista. } \\
\text { Dimensão educativa dos estudos ambientais. Inserção da dimensão ambiental nos } \\
\text { espaços escolares e não escolares. }\end{array}$ \\
\hline $\begin{array}{c}\text { OBJETIVO } \\
\text { GERAL }\end{array}$ & $\begin{array}{l}\text { Refletir sobre a urgência da implementação de uma nova abordagem de educação, } \\
\text { a qual esteja fundamentada no conhecimento científico articulado com o contexto } \\
\text { socioambiental e vise à formação geral do indivíduo incluindo os princípios éticos } \\
\text { e sociais inerentes à função social de cada Profissional. }\end{array}$ \\
\hline $\begin{array}{c}\text { OBJETIVOS } \\
\text { ESPECÍFICOS }\end{array}$ & $\begin{array}{l}\text { Refletir sobre os conceitos e práticas que norteiam a Educação Ambiental; Elaborar } \\
\text { e executar um plano de ação e pesquisa na perspectiva de desenvolvimento de } \\
\text { valores sob a égide da Educação Ambiental. }\end{array}$ \\
\hline CONTEÚDO & $\begin{array}{l}\text { Educação e Educação Ambiental; Educação; Ética; Aspectos históricos e normativos } \\
\text { da Educação Ambiental no mundo e no Brasil; As grandes conferências; Lei da } \\
\text { Politica de Educação Ambiental; Dimensão ambiental; Ambiente; } \\
\text { Interdisciplinaridade; Sustentabilidade; Inserção da dimensão ambiental no ensino } \\
\text { formal e não formal; Ensino formal; Ensino não formal. }\end{array}$ \\
\hline
\end{tabular}

Fonte: Autoras baseadas no programa da disciplina disponível no Sistema Integrado de Gestão de Atividades Acadêmicas (SIGAA) da Universidade Federal de Sergipe (UFS). Acessado por meio do endereço eletrônico: https://www.sigaa.ufs.br/sigaa/link/public/curso/curriculo/12686890.

Observa-se que é objetivo específico dessa disciplina refletir sobre os conceitos e práticas que norteiam a Educação Ambiental, porém não se especifica que conceitos são esses, ou seja, se sociais, políticos, econômicos, ecológicos etc. Não se verifica também a menção a tais conceitos no conteúdo do plano de ensino.

Conforme as DCN-Pedagogia, em seu Artigo $2^{\circ}$, parágrafo $2^{\circ}$, inciso $\mathrm{II}$, o curso de Pedagogia em todo o Brasil propiciará: "Il - a aplicação ao campo da educação, de contribuições, entre outras, de conhecimentos como o filosófico, o histórico, o antropológico, o ambiental-ecológico, o psicológico, o lingüístico, o sociológico, o político, o econômico, o cultural." (BRASIL, 2006, p. 1, grifo nosso). Porém, não se especifica o núcleo responsável por essa atribuição e, também, os componentes curriculares destinados a esse fim, assim como não se esclarece como se dará essa aplicação. De acordo com a Resolução $n^{\circ} 2 / 2015$, essa aplicação é propiciada pelo 
[...] núcleo de aprofundamento e diversificação de estudos das áreas de atuação profissional, incluindo os conteúdos específicos e pedagógicos, priorizadas pelo projeto pedagógico das instituições, em sintonia com os sistemas de ensino, que, atendendo às demandas sociais, oportunizará, entre outras possibilidades: [...]; d) Aplicação ao campo da educação de contribuições e conhecimentos, como o pedagógico, o filosófico, o histórico, o antropológico, o ambiental-ecológico, o psicológico, o linguístico, o sociológico, o político, o econômico, o cultural; [...]. (BRASIL, 2015, p. 10).

O Núcleo de Aprofundamento e Diversificação de Estudos, no projeto do curso de Pedagogia da UFS do Campus São Cristóvão, "[...] tem por base a investigação/pesquisa em educação como elemento fundante da prática docente em diferentes ambientes institucionais ou comunitários." (UFS, 2008, p. 4). Está composto pelos seguintes componentes curriculares: Seminários de Estudos / e I/; Monografia / e // e Tópicos Especiais em Educação / e II. Não se verificou na proposta pedagógico-curricular analisada, mais especificamente nas ementas desses componentes identificados, a menção à aplicação do conhecimento ambiental-ecológico ao campo da educação.

Segundo Araújo (2004, p. 74), “[...], não se espera da universidade a introdução nos currículos de uma nova disciplina com conteúdos e metodologias de educação ambiental. Isso feriria os princípios dessa educação, mas a criação de um espaço que discuta o campo e a finalidade da educação ambiental." O componente curricular Educação e Ética Ambiental, apesar de ser uma disciplina, configura-se nesse espaço de discussão sobre a Educação Ambiental, pois tem como objetivo principal refletir sobre a urgência da implementação da Educação Ambiental, visando a formação integral do indivíduo, incluindo os princípios éticos e sociais essenciais à função social de cada profissional.

Temos nessa disciplina a abordagem da Educação Ambiental não reduzida apenas ao aspecto natural ou ecológico. "Ainda assim, muitas vezes esse ensino ocorre somente de forma naturalista, ou seja, limitado ao desenvolvimento de atividades voltadas à vivência na e com a natureza, o que pode levar os indivíduos à falta de preocupação com as consequências de suas ações." (RODRIGUES; SAHEB, 2018, p. 577). Essa pode ser considerada uma justificativa plausível para a necessidade de uma disciplina no currículo de formação de professores(as) para a abordagem da questão ambiental em suas dimensões social, econômica, cultural, ética e política, sendo a Educação Ambiental transformadora ou para a mudança da realidade socioambiental, o que a faz se distanciar de uma concepção tradicional ou conservadora, pautada apenas na "[...] transmissão de conhecimento e na mudança de comportamento em relação à conservação da natureza. A educação, baseada nesta concepção, considera, predominantemente, os aspectos naturais sem correlacionálos aos aspectos sociais, culturais etc." (LIMA; OLIVEIRA, 2011, p. 325). Contrariamente a essa concepção, Adorno (1995, p. 141) assim nos apresenta a educação: 
Evidentemente não a assim chamada modelagem de pessoas, porque não temos o direito de modelar pessoas a partir do seu exterior; mas também não a mera transmissão de conhecimentos, cuja característica de coisa morta já foi mais do que destacada, mas a produção de uma consciência verdadeira. (grifo do autor).

Para o filósofo, a consciência não é apenas a capacidade formal de pensar, mas pensar em relação à realidade e à tarefa da educação, diante das mudanças sociais, seria intermediar essa consciência ou desenvolver o processo de conscientização, conduzindo o indivíduo para um comportamento emancipado e crítico. Nesse contexto, "A EA, enquanto dimensão fundamental da educação contemporânea, contribui para a construção crítica do conhecimento transformador da realidade socioambiental." (CARNEIRO, 2006, p. 27).

É importante salientar que essa análise se deu a partir da observação dos componentes curriculares explícitos que trabalham a Educação Ambiental no curso de Pedagogia da UFS, ou seja, os que trazem a expressão no título e nas ementas. Entretanto, não podemos deixar de considerar que existem outras possibilidades de a Educação Ambiental ser trabalhada no curso em tela, visto que o currículo é dinâmico e os elementos implícitos podem ter muito a revelar em estudos futuros.

\section{Conclusão}

A implementação da Educação Ambiental de forma integrada aos conteúdos obrigatórios do Ensino Fundamental e do Ensino Médio é determinada por um dispositivo legal, mas antes necessita ser um compromisso, individual e coletivo, dos cursos de licenciatura e do professorado, uma vez conscientes da importância e imprescindibilidade dessa dimensão do tema nos currículos do Ensino Superior e da Educação Básica. Ou seja, é preciso haver um empenho dos cursos superiores em prover uma formação que prepare os professores e as professoras para a Educação Ambiental e empenho, também, desses(as) docentes em implementar essa perspectiva educativa em sala de aula.

Nessa direção, o curso de Licenciatura em Pedagogia da Universidade Federal de Sergipe (UFS) do Campus São Cristóvão, mediante a abordagem crítica da Educação Ambiental, coerentemente com os fundamentos teóricos e epistemológicos da Educação Ambiental Crítica, não insere os conceitos ecológicos nas ementas e nos pressupostos teóricos da proposta pedagógico-curricular, porém, ao inserir a disciplina Educação e Ética Ambiental, sinaliza a utilização do conhecimento da ecologia para desencadear um novo pensamento acerca de sua responsabilidade com o meio.

Vale ressaltar que a presença da disciplina no currículo do curso se destina a munir os(as) futuros(as) professores e professoras de conhecimentos teóricos e metodológicos para a implementação da Educação Ambiental nas séries iniciais do Ensino Fundamental, e para tanto se faz necessário haver conhecimentos de vários campos, a exemplo do ecológico, a fim de alunos(as) e docentes serem capazes de construir um conhecimento 
complexo sobre o ambiente do qual fazem parte.

\section{Referências}

ADORNO, Theodor W. Educação e emancipação. Tradução Wolfgang Leo Maar. 4. ed. Rio de Janeiro: Paz e Terra, 1995.

AHLERT, Alvori. A eticidade da educação: o discurso de uma práxis solidária/universal. ljuí: Ed. Unijuí, 1999.

ARAÚJO, M. I. O. A dimensão ambiental nos currículos de formação de professores de Biologia. Tese (Doutorado em Educação) - Programa de Pós-Graduação da Faculdade de Educação da Universidade de São Paulo, São Paulo, SP, 2004.

ARAÚJO, M. I. O. A universidade e a formação de professores para a educação ambiental.

Rev. Bras. de Educação Ambiental, Brasília, n. 0, p. 71-78. nov. 2004.

BRASIL. Base Nacional Comum Curricular. Brasília: Ministério da Educação, 2017. Disponível em:

$<$ http://basenacionalcomum.mec.gov.br/images/BNCC_El_EF_110518_versaofinal_site.pdf . Acesso em: 29 set. 2020.

BRASIL. Conselho Nacional de Educação. Resolução CNE $/ C P n^{\circ} 1$, de 15 de maio de 2006. Institui Diretrizes Curriculares Nacionais para o Curso de Graduação em Pedagogia, licenciatura. Diário Oficial da União. Brasília, 16 maio. 2006. Seção 1, p. 11. BRASIL. Conselho Nacional de Educação. Resolução CNE $/ C P n^{\circ} 2$, de $1^{\circ}$ de julho de 2015. Define as Diretrizes Curriculares Nacionais para a formação inicial em nível superior (cursos de licenciatura, cursos de formação pedagógica para graduados e cursos de segunda licenciatura) e para a formação continuada. Diário Oficial da União. Brasília, 2 jul. 2015. Seção 1, pp. 8-12.

BRASIL. Lei ${ }^{\circ}$ 9.394, de 20 de dezembro de 1996. Estabelece as diretrizes e bases da educação nacional. Diário Oficial da União. Brasília, 23 dez. 1996. Disponível em: http://www.planalto.gov.br/ccivil_03/leis/L9394.htm. Acesso em: 15 dez. 2019.

Resolução $n^{\circ} 2$, de 15 de junho de 2012. Estabelece as Diretrizes Curriculares Nacionais para a Educação Ambiental. Diário Oficial da União, Brasília, 2012. Disponível em: portal.mec.gov.br/dmdocuments/publicacao13.pdf. Acesso em: 09 jul. 2021.

BOFF, Leonardo. Sustentabilidade: O que é? O que não é?. 5. ed. Petrópolis: Vozes, 2016. BOTON, Jaiane de Moraes et al. O meio ambiente como conformação curricular na formação docente. Rev. Ensaio, Belo Horizonte, v. 12, n. 03, p. 41-50. set.-dez. 2010. Disponível em: http://www.scielo.br/pdf/epec/v12n3/1983-2117-epec-12-0300041.pdf . Acesso em: 12 mar. 2021.

BRETAS, Silvana Aparecida. A atual reformulação do curso de Pedagogia da UFS, segundo 
as Diretrizes Nacionais Curriculares de Pedagogia/2006. In: FREITAS, Anamaria G. Bueno de; SOBRAL, Maria Neide (Orgs.). História e Memória: o curso de Pedagogia da UFS. São Cristóvão: Editora UFS, 2009. p. 41-53.

CAMBI, Franco. História da pedagogia. Tradução Álvaro Lorencini. São Paulo: Editora Unesp, 1999.

CARNEIRO, Sônia Maria Marchiorato. Fundamentos epistemo-metodológicos da educação ambiental. Rev. Educar, Curitiba, n. 27, p. 17-35, 2006. Disponível em:

http://www.scielo.br/pdf/er/n27/a03n27.pdf . Acesso em: 12 mar. 2021.

DIAS, Genebaldo Freire. Educação ambiental: princípios e práticas. 9. ed. São Paulo: Gaia, 2004.

FLICK, Uwe. Intrdução à pesquisa qualitativa. 3. ed. Porto Alegre: Artmed, 2009.

FREIRE, Paulo. Pedagogia da autonomia: saberes necessários à prática educativa. 55. ed. São Paulo: Paz e Terra, 2017.

GOLDENBERG, Mirian. A arte de pesquisar: como fazer pesquisa qualitativa em Ciências Sociais. 13. ed. Rio de Janeiro: Editora Record, 2013.

KANT, I. Sobre a pedagogia. Tradução de Francisco Cock Fontanella. 2. ed. Piracicaba: Editora Unimep, 1999.

LIBÂNEO, José Carlos. Pedagogia e pedagogos, para quê?. 12. ed. São Paulo: Cortez, 2010. LIMA, Aguinel Messias de; OLIVEIRA, Haydée Torres de. A (re)construção dos conceitos de natureza, meio ambiente e educação ambiental por professores de duas escolas públicas.

Rev. Ciência \& Educação, v. 17, n. 2, p. 321-337. 201 1. Disponível em:

http://www.scielo.br/pdf/ciedu/v17n2/a05v17n2.pdf. Acesso em: 12 mar. 2021.

LOUREIRO, Carlos Frederico Bernardo; LAYRARGUES, Philippe Pomier. Ecologia Política, Justiça e Educação Ambiental Crítica: perspectivas de aliança contra-hegemônica.

Trabalho, Educação e Saúde, v. 11, n. 1, p. 53-71, 2013.

MODESTO, Mônica Andrade; SANTOS, Tatiana Ferreira dos. Atuação dos educadores ambientais e a (re)construção de sociedades sustentáveis: constructo de uma transformação possível. Revista Brasileira de Educação Ambiental, v. 15, n. 4, p. 528-548, 2020. Disponível em: https://periodicos.unifesp.br/index.php/revbea/article/view/10828 . Acesso em: 12 jun. 2021.

MOREIRA, Herivelto; CALEFFE, Luiz Gonzaga. Metodologia da pesquisa para o professor pesquisador. Rio de Janeiro: Lamparina, 2008.

MORIN, Edgar. Os sete saberes necessários à educação do futuro. Tradução de Catarina Eleonora F. da Silva e Jeanne Sawaya. 2. ed. São Paulo: Cortez, 2011.

PERRENOUD, Philippe. Escola e cidadania: o papel da escola na formação para a democracia. Tradução de Fátima Murad. Porto Alegre: Artmed, 2005. 
RODRIGUES, Daniela Gureski; SAHEB, Daniele. A educação ambiental na educação infantil segundo os saberes de Morin. Rev. Bras. Estud. Pedagog., Brasília, v. 99, n. 253, p. 573588, set.-dez. 2018. Disponível em: http://www.scielo.br/pdf/rbeped/v99n253/21766681-rbeped-99-253-573.pdf. Acesso em: 12 mar. 2021.

SAVIANI, Dermeval. Escola e democracia. 32. ed. Campinas: Autores Associados, 1999.

SCHMITZ, Egidio Francisco. O Pragmatismo de Dewey na educação: esboço de uma filosofia da educação. Rio de Janeiro: Livros Técnicos e Científicos, 1980.

SERGIPE. Secretaria de Estado da Educação. Currículo de Sergipe: Educação Infantil e Ensino Fundamental. Governo do Estado de Sergipe, Aracaju, SE, 2019. Disponível em: http://basenacionalcomum.mec.gov.br/images/implementacao/curriculos_estados/docum ento_curricular_se.pdf . Acesso em: 29 set. 2020.

UNIVERSIDADE FEDERAL DE SERGIPE. Conselho do Departamento de Educação. Projeto Pedagógico do Curso de Pedagogia. Documento que dispõe a implementação de reforma curricular. UFS/DED, 2007.

UNIVERSIDADE FEDERAL DE SERGIPE. Estrutura Curricular. Disponível em: http://sigaa.ufs.br/sigaa/link/public/curso/curriculo/12686625. Acesso em: 11 ago. 2020.

UNIVERSIDADE FEDERAL DE SERGIPE. Estrutura Curricular. Disponível em: http://sigaa.ufs.br/sigaa/link/public/curso/curriculo/12686890. Acesso em: 11 ago. 2020.

UNIVERSIDADE FEDERAL DE SERGIPE. Plano de Desenvolvimento Institucional (PDI) 20162020. São Cristóvão: Universidade Federal de Sergipe, 2016. Disponível em: https://oficiais.ufs.br/uploads/page_attach/path/1005/PDI-UFS_2016-2020_1_-min.pdf . Acesso em: 17 set. de 2020.

UNIVERSIDADE FEDERAL DE SERGIPE. Resolução n²5/CONEPE, de 2008. Aprova o Projeto Pedagógico do Curso de Graduação em Pedagogia - Licenciatura do campus São Cristóvão da Universidade Federal de Sergipe e dá outras providências. São Cristóvão, SE, 2008. 


\section{Cássia Machado Ribeiro Dantas}

Graduada em Pedagogia pela Universidade Federal de Sergipe (UFS). Especialista em Gestão de Pessoas. Mestranda em Educação pelo Programa de Pós-Graduação em Educação (PPGED/UFS). Email: dantas.pesquisaemeducacao@gmail.com. ORCID: https://orcid.org/0000-0001-7989-2803.

\section{Maria Inêz Oliveira Araújo}

Doutora em Educação pela Universidade de São Paulo (USP). Professora do Programa de PósGraduação em Educação (PPGED) da Universidade Federal de Sergipe (UFS). Líder do Grupo de Estudos e Pesquisas em Educação Ambiental do estado de Sergipe (GEPEASE). E-mail: inez@ufs.br. ORCID: https://orcid.org/0000-0003-2429-1175. 